\title{
Erratum
}

\section{Synthesis of poly(methylmethacrylate)/montmorillonite nanocomposites via in situ intercalative suspension and emulsion polymerization}

by Hisham Essawy, Ahmed Badran, Ahmed Youssef, Abu El-Fetoh Abd El-Hakim

published in Polymer Bulletin 53 (2004) 1, 9-17

DOI 10.1007/s00289-004-0312-y

Published online: 19 January 2005 - C Springer-Verlag 2005

Unfortunately in this contribution an entire paragraph got lost in the production process. So the text below should be inserted directly above Fig. 5 on page 14 .

This means that the polymerization was more favorable in the case of organoclay. As the growing polymer chains increase in length, it prefer the intercalation into the basal space due to its organophilic nature while in the case of the untreated clay the PPS as an anion can be easily intercalated into the basal space which is of hydrophilic nature and start the polymerization. It is worthy to mention that the use of PPS in such cases especially with the untreated montmorillonite is applicable only with the monomers that are partially soluble in water. A trial was made to conduct the polymerization process using different concentrations of PPS beside BPO and it was found that the use of these initiators together invoked better exfoliation as revealed in Fig. 5, on the other hand, the yield did not change appreciably in comparison with using either of the initiators alone. 